\title{
New insights on the theoretical study of hydrolysis mechanism of carbon disulfide (CS2) at low temperature: A density functional theory study
}

\section{Yue Wang \\ Yunnan University https://orcid.org/0000-0003-0928-5455}

\section{Guijian Zhang}

Kunming University of Science and Technology

\section{Xin Shi}

Yunnan University

\section{Ming Deng}

Yunnan University

Lihong Tang ( $\nabla$ lihongtang@ynu.edu.cn )

Yunnan University

\section{Zhiyuan Ning}

Yunnan University

\section{Research Article}

Keywords: DFT, Carbon Disulfide, Hydrolysis, Reaction Mechanism, Reaction kinetic

Posted Date: January 11th, 2022

DOI: https://doi.org/10.21203/rs.3.rs-1165681/v1

License: (c) (1) This work is licensed under a Creative Commons Attribution 4.0 International License. Read Full License 


\section{Abstract}

Density functional theory (DFT) is used to investigate the two-step hydrolysis mechanism of $\mathrm{CS}_{2}$. By optimizing the structure of reactants, intermediates, transition states, and products, the conclusion shows that the first step of $\mathrm{CS}_{2}$ ( $\mathrm{CS}_{2}$ reacts with $\mathrm{H}_{2} \mathrm{O}$ first to form COS intermediate); The second step (COS intermediate reacts with $\mathrm{H}_{2} \mathrm{O}$ to form $\mathrm{H}_{2} \mathrm{~S}$ and $\mathrm{CO}_{2}$ ). Therefore, hydrogen migration is crucial to the mechanism of $\mathrm{CS}_{2}$ hydrolysis. In the first step of the reaction, the rate-determining step in both the single $\mathrm{C}=\mathrm{S}$ path and the double $\mathrm{C}=\mathrm{S}$ path has a higher barrier of $199.9 \mathrm{~kJ} / \mathrm{mol}$, but the $127.9 \mathrm{~kJ} / \mathrm{mol}$ barrier in the double $\mathrm{C}=\mathrm{S}$ path has a lower barrier of $142.8 \mathrm{~kJ} / \mathrm{mol}$ in the single $\mathrm{C}=\mathrm{S}$ path. So the double $\mathrm{C}=\mathrm{S}$ path is better. Similarly, the order of the barriers for the three paths in the second reaction is $\mathrm{C}=\mathrm{S}$ path $\angle \mathrm{C}=\mathrm{S}$ path and $\mathrm{C}=\mathrm{O}$ path $\angle \mathrm{C}=\mathrm{O}$ path. So the $\mathrm{C}=\mathrm{S}$ path is better. Also, to further explore the reaction of $\mathrm{CS}_{2}$ hydrolysis, the natural bond orbital (NBO) analysis of the transition states was carried out. Besides, to further explain which reaction path is better, the hydrolysis kinetics of $\mathrm{CS}_{2}$ was analyzed. It was found that the hydrolysis of $\mathrm{CS}_{2}$ was an exothermic reaction, and the increase in temperature was unfavorable to the reaction. During the hydrolysis of $\mathrm{CS}_{2}$, the six reaction paths are parallel and competitive. The results will provide a new way to study the catalytic hydrolysis of $\mathrm{CS}_{2}$.

\section{Introduction}

In today's society, the emission of gaseous sulfur pollutants has received extensive attention. Sulfurcontaining waste gas can be generally divided into two categories: organic sulfur and inorganic sulfur. Carbon disulfide $\left(\mathrm{CS}_{2}\right)$ and carbonyl sulfur (COS) are typical organic sulfides that are difficult to be removed, which mainly come from the emission of sulfur-containing tail gas in the industrial production process, and widely exist in gas, natural gas, water gas, coke oven gas, and Kraus tail gas [1-5]. When carbon disulfide and carbonyl sulfur diffuse into the atmosphere, it will cause serious hurt to human health and therefore the ecological atmosphere [6-10]. Given the serious harm of $\mathrm{CS}_{2}$ to human beings, it is particularly important to develop an efficient method to remove $\mathrm{CS}_{2}$ from industrial waste gas [11]. The removal of $\mathrm{CS}_{2}$ can be divided into two categories: dry and wet [12-14]. The catalytic hydrolysis method in the dry process can hydrolyze $\mathrm{CS}_{2}$ to $\mathrm{H}_{2} \mathrm{~S}$ and $\mathrm{CO}_{2}$ at a low temperature, and the $\mathrm{H}_{2} \mathrm{~S}$ product can be further catalyzed and oxidized into elemental $S$ for recycling [15-17]. Therefore, catalytic hydrolysis is widely used attributable to its delicate reaction conditions and high conversion rate $[18,19]$. In the experiment, a lot of achievements have been made in the study of $\mathrm{CS}_{2}$ catalytic hydrolysis. In particular, Ning Group realized the low temperature $\left(<100^{\circ} \mathrm{C}\right)$ catalytic hydrolysis of $\mathrm{CS}_{2}$ through the preparation of the catalyst, laying a foundation for the industrialization of $\mathrm{CS}_{2}$ low-temperature catalytic hydrolysis [2024]. However, it is not enough to check the hydrolysis of $\mathrm{CS}_{2}$ solely from the perspective of the experiment without theoretical research, and the hydrolysis mechanism of $\mathrm{CS}_{2}$ is not completely the same in theory. Therefore, thinking about the essence of $\mathrm{CS}_{2}$ hydrolysis is crucial to improve our understanding of $\mathrm{CS}_{2}$ hydrolysis and to better clarify our exploration. In computational chemistry, density functional theory (DFT) is wide accustomed to exploring the energy and structure of molecules, the energy and structure of 
transition states, the vibration frequency, the energy of chemical reactions, and so on. It is a computational chemistry technique that can explore the mechanism of reaction at the molecular level [25-29]. Such as, Bohn et al. have investigated a theoretical study of the adduct $\mathrm{H}+\mathrm{CS}_{2}$ [30]. The reaction of $\mathrm{N}+\mathrm{CS}_{2}$ was investigated using DFT at B3LYP/6-311+G** and CCSD/6-311+G* levels of theory, and the theoretical result conformed with experimental observation [31]. Vahid Saheb also studied the reaction mechanism of $O$ with $\mathrm{CS}_{2}$ using DFT in levels of B3LYP/6-311+G (d, p). And the theoretical result revealed that the products of the reaction of $\mathrm{CS}_{2}+\mathrm{O}$ are $\mathrm{CS}$ and $\mathrm{SO}$, also in agreement with experimental observation [32]. Jianqiang Zhao et al. used DFT to perform geometric optimization on all azobenzene at the B3LYP/6-311+G(d, p) theoretical level, and the structure proved to be reliable for describing the structure and properties of organic molecules, the theoretical calculation agrees with the experiment [33]. Hong Tian et al. used DFT to review the method of biochar conversion to gaseous products under the action of $\mathrm{CO}_{2}$ at the B3LYP/6-31G(d, p) level. The energy of activation and thermodynamic parameters of every reaction step was obtained by analyzing all the substances in the gasification process [34]. Becke's three-parameter hybrid Lee-Yang-Parr exchange-correlation functional (B3LYP) [35] was used to determine calculational authenticity due to its ability to provide reasonable results. Through relevant theoretical and experimental cases in the above literature, we can find that it is appropriate to use the theoretical method of B3LYP in this study. Grimme pointed out in the Journal of Chemical that DFT-D3 is free and the most popular method of dispersion correction and can be used to optimize various types of weakly interacting systems [36]. In the Journal of Computational Chemistry, Grimme found that using Becke-Johnson damping, which has a clearer physical meaning, can make the results slightly better. The description advantage is more significant for the intra-molecular dispersion effect, and this correction form is commonly referred to as DFT-D3(BJ) [37]. Later, a large number of researchers have used DFTD3(BJ). For example, Lu Tian's research group mentioned in the journal J. Mol. Model that the calculation results of hydrogen and nitrogen dimers with and without DFT-D3 correction of B3LYP showed that B3LYP could not obtain the stable dimer configuration at all. With DFT-D3 correction, namely B3LYP-D3, the calculated results of interaction energy for these dimers are qualitatively consistent with $\operatorname{CCSD}(T)$ [38]. Therefore, this paper uses DFT-D3 (BJ) to carry out relevant research.

Therefore, in this study, the optimal level of B3LYP-D3(BJ)/6-311+G* was selected to study the mechanism of $\mathrm{COS}, \mathrm{H}_{2} \mathrm{~S}$, and $\mathrm{CO}_{2}$ generation caused by $\mathrm{CS}_{2}$ hydrolysis in the absence of the catalyst [24], experimental studies have shown that $\mathrm{CS}_{2}$ can also be hydrolyzed at room temperature [19]. By exploring the intermediate state (IM) and transition state (TS) in the process of $\mathrm{CS}_{2}$ hydrolysis, the mechanism of $\mathrm{CS}_{2}$ hydrolysis reaction was clarified in detail, and the most favorable path of $\mathrm{CS}_{2}$ hydrolysis was found out. Besides, by exploring the reaction kinetics of $\mathrm{CS}_{2}$ hydrolysis and analyzing the natural bond orbital donor-acceptor interaction, this process was deeply analyzed, hoping to produce a brand-new reference for the catalytic hydrolysis of $\mathrm{CS}_{2}$.

\section{Theoretical Methods And Models}


The DFT method is used and calculated in Gaussian 09 [39]. The reactants, intermediates, and products were optimized at the levels of B3LYP-D3(BJ)/6-311+G*. Also, unrestricted rotation was selected. The quadratic synchronous transit (QST) method is used to search for TS to find the possible TS structure. The computational level of density functional theory is performed to measure the reliability of bond lengths, angles, etc. On the other hand; each molecule is subjected to vibration analysis and treated as a basis, either as an intermediate with no virtual frequency or as a TS with an imaginary frequency $[33,40]$. Zero-point vibration energy and electron energy are calculated. Also, an IRC calculation is performed to ensure that all transition states are connected to the desired reactants and products. Furthermore, to determine that the transition states found are all connected to the desired reactants and products, we calculate the intrinsic reaction coordinate (IRC). Moreover, the interaction between orbitals in the compound was vividly demonstrated by Natural Bonding Orbital (NBO) calculation. The results of NBO were analyzed by Multiwfn program [41] and VMD program [42]. The reaction rate constants at 298.15K $\sim 1000 \mathrm{~K}$ were calculated using transition state theory (TST) [43].

\section{Results And Discussion}

\subsection{Reaction mechanism}

In this study, we assume that the mechanism of $\mathrm{CS}_{2}$ hydrolysis only includes two steps, the first step: $\mathrm{CS}_{2}$ $+\mathrm{H}_{2} \mathrm{O} \rightarrow \mathrm{COS}+\mathrm{H}_{2} \mathrm{~S}$; the second step: $\mathrm{COS}+\mathrm{H}_{2} \mathrm{O} \rightarrow \mathrm{H}_{2} \mathrm{~S}+\mathrm{CO}_{2}$.

\subsubsection{The first step of the reaction mechanism of $\mathrm{CS}_{2}$ hydrolysis}

In the first step of the mechanism for $\mathrm{CS}_{2}$ hydrolysis, two reaction paths will be discussed according to two optimized geometries (Fig. 1) and schematic potential energy surfaces. The two reaction paths are as follows:

the single $\mathrm{C}=\mathrm{S}$ path: $\mathrm{CS}_{2}+\mathrm{H}_{2} \mathrm{O} \rightarrow \mathrm{IM} 1 \rightarrow \mathrm{TS} 1 \rightarrow \mathrm{IM} 2-1 \rightarrow \mathrm{TS} 2 \rightarrow \mathrm{IM} 3 \rightarrow \mathrm{COS}+\mathrm{H}_{2} \mathrm{~S}$.

the double $\mathrm{C}=\mathrm{S}$ path: $\mathrm{CS}_{2}+\mathrm{H}_{2} \mathrm{O} \rightarrow \mathrm{IM} 1 \rightarrow \mathrm{TS} 1 \rightarrow \mathrm{IM} 2-1 \rightarrow \mathrm{TS} 2^{\prime} \rightarrow \mathrm{IM} 3^{\prime}-1 \rightarrow \mathrm{TS} 3^{\prime} \rightarrow \mathrm{IM} 3 \rightarrow \mathrm{COS}+\mathrm{H}_{2} \mathrm{~S}$.

For the single $\mathrm{C}=\mathrm{S}$ path, firstly, a $\mathrm{CS}_{2}$ molecule reacts with an $\mathrm{H}_{2} \mathrm{O}$ molecule and forms the intermediate (IM1), which also was called corresponding reactant complexes. IM1 is that the reactant-like intermediate during which oxygen atom on water attacks carbon atom on $\mathrm{CS}_{2}$. The energy of IM1 is slightly higher than the total energy of the reactants $\mathrm{CS}_{2}$ and $\mathrm{H}_{2} \mathrm{O}$ by $13.3 \mathrm{~kJ} / \mathrm{mol}$. As a result of van der Waals forces, these two reactant molecules could interact with each other. Meanwhile, there are also weaker electrostatic interactions between hydrogen atoms and sulfur atoms. But, it is difficult for IM1 to transfer the proton directly from the 04-atom of water to S2-atom of $\mathrm{CS}_{2}$ due to the longer C1-04 (3.453A) and S2$\mathrm{H} 5$ (2.725 $\mathrm{A}$ ) distances in IM1. Thus, in the reaction between $\mathrm{CS}_{2}$ and $\mathrm{H}_{2} \mathrm{O}$, the distance between $\mathrm{CS}_{2}$ and 
$\mathrm{H}_{2} \mathrm{O}$ is gradually reduced under the action of van der Waals force. And the original linear $\mathrm{CS}_{2}$ molecule is distorted $\left(\angle \mathrm{S} 2-\mathrm{C} 1-\mathrm{S} 3\right.$ from $180^{\circ}$ to $\left.142.2^{\circ}\right)$, and IM2-1 is made via TS1 with the imaginary frequency of $-1573.61 \mathrm{i} / \mathrm{cm}$. The highly strained ring TS1, with a smaller angle of hydrogen bond $\left(113.1^{\circ}\right)$, almost

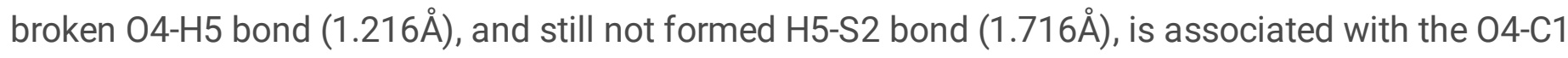
bond stretch and the migration of $\mathrm{H} 5$ from $\mathrm{O} 4$ to S2. Through rotation along with the C1-S2 bond, IM2-1 can be converted orderly into its isomer IM2-2 and IM2-3 accompanying a rotation barrier of $38.9 \mathrm{~kJ} / \mathrm{mol}$ and $-1.2 \mathrm{~kJ} / \mathrm{mol}$, respectively; subsequently, through rotation along with the C1-04 bond, IM2-3 can also be converted orderly into its isomer IM2-4 and IM2-5 accompanying a rotation barrier of $49.9 \mathrm{~kJ} / \mathrm{mol}$ and $26.7 \mathrm{~kJ} / \mathrm{mol}$, respectively. Finally, $\mathrm{H} 6$ migrates from $\mathrm{O} 4$ to $\mathrm{S} 2$ to form IM3, and the $04-\mathrm{H} 6$ bond is $2.401 \mathrm{~A}$, indicating that $\mathrm{H}_{2} \mathrm{~S}$ is separated from the initial complex to form COS. So the stretching of 04-C1 bond, $\mathrm{H} 6$ migrates from $\mathrm{O} 4$ to $\mathrm{S} 2$, forming a transitional state of quaternary ring TS2 with an imaginary frequency of $-1712.30 \mathrm{i} / \mathrm{cm}$.

For the double $\mathrm{C}=\mathrm{S}$ path, the formation of IM2-1 remains unchanged for the single $\mathrm{C}=\mathrm{S}$ path. However, $\mathrm{H} 6$ may also first transfer to $\mathrm{S} 3$ atom through another four-membered ring TS2', its imaginary frequency is $-1755.11 \mathrm{i} / \mathrm{cm}$, showing the stretching pattern of $\mathrm{S} 3-\mathrm{C} 1$ and also the migration of $\mathrm{H} 6$ from $\mathrm{O} 4$ to $\mathrm{S} 3$, to form IM3'-1. Subsequently, through rotation along with the C1-S3 bond, IM3'-1 can be converted orderly into its isomer IM3'-2 and IM3'-3 accompanying a rotation barrier of $28.6 \mathrm{~kJ} / \mathrm{mol}$ and $4.8 \mathrm{~kJ} / \mathrm{mol}$, respectively. Its last step refers to the formation of $\mathrm{H}_{2} \mathrm{~S}$ via a four-membered ring TS structure TS3', its imaginary frequency is $-1317.63 \mathrm{i} / \mathrm{cm}$, showing the stretching pattern of S2-C1 and the migration of $\mathrm{H} 6$ from S3 to S2, the by-product IM3 formed. Similarly, in IM3, $\mathrm{H}_{2} \mathrm{~S}$ and COS are formed.

Table 1

Imaginary frequency of each transition state and the bonds corresponding to relative normal vibrations for the hydrolysis of $\mathrm{CS}_{2}$

\begin{tabular}{|lll|}
\hline Transition state & Imaginary frequency $(\mathrm{i} / \mathrm{cm})$ & Bonds corresponding to normal vibrations \\
\hline TS1 & -1573.61 & H5-O4-S2; O4-C1 \\
\hline TS2 & -1712.30 & H6-O4-S2; S2-C1 \\
\hline TS2 & -1755.11 & H6-O4-S3; S3-C1 \\
\hline TS3' & -1317.63 & S3-S2-H6; S2-C1 \\
\hline
\end{tabular}

According to the analysis of two reaction paths in the first step reaction mechanism of $\mathrm{CS}_{2}$ hydrolysis, It pinpoints that $\mathrm{H}$ migration is crucial in the first step reaction mechanism of $\mathrm{CS}_{2}$ hydrolysis. By exploring the reaction path, the reaction energy barriers of the single $\mathrm{C}=\mathrm{S}$ path and double $\mathrm{C}=\mathrm{S}$ path are shown in Fig. 2. The results show that the two paths, $(\mathrm{IM} 1 \rightarrow \mathrm{IM} 2-1)$ are the rate-determining steps, its energy barrier is $182.7 \mathrm{~kJ} / \mathrm{mol}$. However, the energy barrier of the step (IM2-1 $\rightarrow \mathrm{TS} 2)(146.287 \mathrm{~kJ} / \mathrm{mol})$ in single $\mathrm{C}=\mathrm{S}$ path is higher than those for the step (IM2-1 $\rightarrow$ TS2') $(107 \mathrm{~kJ} / \mathrm{mol})$ and the step (IM3'-1 $\rightarrow$ TS3') $(122.4$ $\mathrm{kJ} / \mathrm{mol}$ ) in double $\mathrm{C}=\mathrm{S}$ path. Therefore, it's not surprising that the double $\mathrm{C}=\mathrm{S}$ path is better. 
To further explore the first step reaction of $\mathrm{CS}_{2}$ hydrolysis, NBO analysis of transition states TS2 and TS2 was carried out using the Second-order Perturbation theory. the second-order stabilization energy is a measure for the strength of the electron donor-acceptor interaction [44-48]. Fig.3 shows the NBO overlap of electron donating from the lone pair of S2 to the antibonding acceptor of $\sigma^{\star}(\mathrm{O} 4-\mathrm{H} 6)$ in TS2, and from the lone pair of S3 to the antibonding acceptor of $\sigma^{\star}(\mathrm{S} 2-\mathrm{H} 6)$ in TS2'. The second-order stabilization energy, also shown in Fig.3, is $717.2 \mathrm{~kJ} / \mathrm{mol}$ for the $\mathrm{LP}(\mathrm{S} 3) \rightarrow \sigma^{\star}(\mathrm{S} 2-\mathrm{H} 6)$ in TS2', which is larger than $\mathrm{LP}(\mathrm{S} 2) \rightarrow \sigma^{\star}(\mathrm{O} 4-\mathrm{H} 6)$ in TS2 $(481.2 \mathrm{~kJ} / \mathrm{mol})$. It indicates [IMAGE-

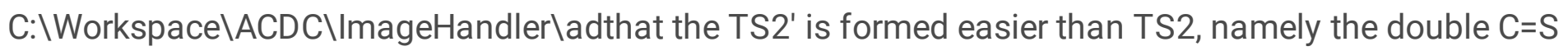
path is better.

\subsubsection{The second step of the reaction mechanism of $\mathrm{CS}_{2}$ hydrolysis}

In the second step of the mechanism for $\mathrm{CS}_{2}$ hydrolysis, three reaction paths will be discussed according to two the optimized geometries and schematic potential energy surfaces. The three reaction paths are as follows:

the $\mathrm{C}=\mathrm{S}$ path: $\mathrm{COS}+\mathrm{H}_{2} \mathrm{O} \rightarrow \mathrm{IM} 4 \rightarrow \mathrm{TS} 4 \rightarrow \mathrm{IM} 5-1 \rightarrow \mathrm{TS} 5 \rightarrow \mathrm{IM} 6 \rightarrow \mathrm{CO}_{2}+\mathrm{H}_{2} \mathrm{~S}$

the $\mathrm{O}=\mathrm{C}$ path: $\mathrm{COS}+\mathrm{H}_{2} \mathrm{O} \rightarrow \mathrm{IM} 4 \rightarrow \mathrm{TS} 4^{\prime} \rightarrow \mathrm{IM} 5^{\prime}-1 \rightarrow \mathrm{TS} 5^{\prime} \rightarrow \mathrm{IM} 5-5 \rightarrow \mathrm{TS} 5 \rightarrow \mathrm{IM} 6 \rightarrow \mathrm{CO}_{2}+\mathrm{H}_{2} \mathrm{~S}$

the $\mathrm{C}=\mathrm{S}$ path and the $\mathrm{O} \mathrm{O}=\mathrm{C}$ path: $\mathrm{COS}+\mathrm{H}_{2} \mathrm{O} \rightarrow \mathrm{IM} 4 \rightarrow \mathrm{TS} 4 \rightarrow \mathrm{IM} 5-1 \rightarrow \mathrm{TS} 5 " \rightarrow \mathrm{IM} 5-5 \rightarrow \mathrm{TS} 5 \rightarrow \mathrm{IM} 6$

$\rightarrow \mathrm{CO}_{2}+\mathrm{H}_{2} \mathrm{~S}$

For the $\mathrm{C}=\mathrm{S}$ path (Fig. 4), the attack of $\mathrm{H} 2 \mathrm{O}$ on the $\mathrm{C} 1$ atom of $\mathrm{COS}$ leads to the formation of the precoordination complex IM4 because of the van der Waals forces between $\mathrm{H} 2 \mathrm{O}$ and COS. And the original linear COS molecule is gradually distorted. IM4 is $13.7 \mathrm{~kJ} / \mathrm{mol}$ more active than the original reactants $\mathrm{COS}$ and $\mathrm{H} 2 \mathrm{O}$. At the first, the addition of $\mathrm{H} 2 \mathrm{O}$ to $\mathrm{COS}$ is completed upon full $\mathrm{H} 5$ transfer from $\mathrm{H} 2 \mathrm{O}$ to S on COS to form the thiocarbonic acid IM5-1 via TS4, its imaginary frequency is $-1592.47 \mathrm{i} / \mathrm{cm}$ showing 02-C1 stretching and $\mathrm{H} 5$ migration from $\mathrm{O} 4$ to $\mathrm{S} 2$. In TS4, the length of the $\mathrm{O} 4-\mathrm{H} 5$ bond that is almost broken is $1.257 \AA$, and the angle 03-C1-S2 changes from

$180.0^{\circ}$ to $144.2^{\circ}$. Meanwhile, the H5-S2 and 04-C1 bonds are almost formed have lengths of 1.664 and $1.633 \AA$, respectively. The 04-C1 bond shortens from 2.834 to $1.633 \AA$. The energy barrier height of TS4 relative to IM4 is $195.1 \mathrm{~kJ} / \mathrm{mol}$. Then, through rotation along with the S2-C1 bond, IM5-1 can be converted orderly into its isomer IM5-2 and IM5-3 accompanying a rotation barrier of $33.8 \mathrm{~kJ} / \mathrm{mol}$ and $-3.3 \mathrm{~kJ} / \mathrm{mol}$, respectively. Similarly, through also rotation along with the 04-C1 bond, IM5-3 can be converted orderly into its isomer IM5-4 and IM5-5 accompanying a rotation barrier of $45.5 \mathrm{~kJ} / \mathrm{mol}$ and $20.3 \mathrm{~kJ} / \mathrm{mol}$, respectively. Finally, $\mathrm{H} 6$ migrates to S2 to form IM6, and the S2-C1 bond is 3.352A. The stretch of 04-C1 
bond and the migration of $\mathrm{H} 6$ to $\mathrm{S} 2$ form the transition state TS5, whose imaginary frequency is -1752.28 $\mathrm{i} / \mathrm{cm}$. The energy of TS5 is $136.9 \mathrm{~kJ} / \mathrm{mol}$ higher than that of IM5-1.

In the $\mathrm{O}=\mathrm{C}$ path (Fig. 4), a COS molecule reacts with an $\mathrm{H}_{2} \mathrm{O}$ molecule and leads to form the precoordination complex IM4, whose interaction energy of $13.7 \mathrm{~kJ} / \mathrm{mol}$. After the pre-complex IM4 between COS and $\mathrm{H}_{2} \mathrm{O}$ is formed, the following nucleophilic attack of $\mathrm{H}_{2} \mathrm{O}$ leads to the four-membered TS4' with the energy barrier of $260.0 \mathrm{~kJ} / \mathrm{mol}$, which $\mathrm{H} 6$ transfer from $\mathrm{H}_{2} \mathrm{O}$ to O-atom of COS. The imaginary frequency for TS4' is $-1887.88 \mathrm{i} / \mathrm{cm}$, associating with the $04-\mathrm{C} 1$ bond and the migration of $\mathrm{H} 6$ to 03 . After the reaction surmounted TS4', intermediate IM5'-1 is formed. For IM5'-1 with an energy barrier of 91.9 $\mathrm{kJ} / \mathrm{mol}, \mathrm{C} 1-04$ and $\mathrm{C} 1-03$ are $1.347 \AA$ and $1.328 \AA$, respectively. Then the tautomerization of IM5'- 1 leads orderly to its isomer IM5'-2 and IM5'-3, accompanying a rotation barrier of $91.4 \mathrm{~kJ} / \mathrm{mol}$ and $-0.02 \mathrm{~kJ} / \mathrm{mol}$, respectively. Moreover, IM5'-3 is the most relative structure with a view to the next four-membered TS5', its imaginary frequency of $-1755.12 \mathrm{i} / \mathrm{cm}$ showing the stretching pattern of $\mathrm{S} 2-\mathrm{C} 1$ and the migration of $\mathrm{H} 5$ to $\mathrm{S} 2$, to form M5-5, and its energy barrier is $58.4 \mathrm{~kJ} / \mathrm{mol}$. Finally, the remaining two steps of the $\mathrm{O}=\mathrm{C}$ path correspond to the $\mathrm{C}=\mathrm{S}$ path.

From Fig. 4, what's the difference between the $\mathrm{C}=\mathrm{S}$ and $\mathrm{O}=\mathrm{C}$ path and the $\mathrm{C}=\mathrm{S}$ path is the reaction steps (IM5-1 $\rightarrow$ IM5-3). Concerning the $\mathrm{C}=\mathrm{S}$ and $\mathrm{O}=\mathrm{C}$ path, in brief, firstly, $\mathrm{H} 5$ of water transfer from $\mathrm{H}_{2} \mathrm{O}$ to $\mathrm{S} 2-$ atom of COS to form IM5-1; and Secondly, the migration of $\mathrm{H} 6$ from $\mathrm{O} 4$ to $\mathrm{O} 3$ forms the intermediate IM5$3(30.3 \mathrm{~kJ} / \mathrm{mol})$. Thus, these two processes are connected with a vital transition state structure TS5" $(195.6 \mathrm{~kJ} / \mathrm{mol})$, where $\mathrm{H} 6$ transfers to 03. And the imaginary frequency for TS5" is $-1956.90 \mathrm{i} / \mathrm{cm}$.

Table 2

Imaginary frequency of each transition state and the bonds corresponding to relative normal vibrations for the hydrolysis of COS.

\begin{tabular}{|lll|}
\hline Transition state & Imaginary frequency $\left(\mathbf{c m}^{-\mathbf{1}}\right)$ & Bonds corresponding to normal vibrations \\
\hline TS4 & -1592.47 & H5-O4-S2; O4-C1 \\
\hline TS5 & -1752.28 & H6-O4-S2; S2-C1 \\
\hline TS4' & -1887.88 & H6-O3-O4; O4-C1 \\
\hline TS5' & -1755.12 & H5-O4-S2; S2-C1 \\
\hline TS5" & -1956.90 & H6-O3-O4; O3-C1 \\
\hline
\end{tabular}

In the mechanism of $\mathrm{CS}_{2}$ hydrolysis, the transfer of $\mathrm{H}$ is very important. Fig. 5 shows that IM4 $\rightarrow$ TS4 $(195.1 \mathrm{~kJ} / \mathrm{mol})$ is $58.2 \mathrm{~kJ} / \mathrm{mol}$ higher than IM5-1 $\rightarrow$ TS5 $(136.9 \mathrm{~kJ} / \mathrm{mol})$ in terms of reaction energy barrier under the $\mathrm{C}=\mathrm{S}$ path. Under the $\mathrm{C}=0$ path, IM4 $\rightarrow \mathrm{TS} 4{ }^{\prime}(260.0 \mathrm{~kJ} / \mathrm{mol})$ is $150.5 \mathrm{~kJ} / \mathrm{mol}$ and $138.1 \mathrm{~kJ} / \mathrm{mol}$ 
higher than IM5'-1 $\rightarrow$ TS5'(109.5 kJ/mol) and IM5-5 $\rightarrow$ TS5(121.9 kJ/mol), respectively. Meanwhile, the rate-determining steps of the two paths are IM4 $\rightarrow$ IM5-1. For $\mathrm{C}=\mathrm{S}$ and $\mathrm{O}=\mathrm{C}$ paths, IM4 $\rightarrow$ TS4 (195.1 $\mathrm{kJ} / \mathrm{mol})$ is $42.9 \mathrm{~kJ} / \mathrm{mol}$ higher than IM5-1 $\rightarrow$ TS5 " $(152.2 \mathrm{~kJ} / \mathrm{mol})$ and $73.2 \mathrm{~kJ} / \mathrm{mol}$ higher than IM5$5 \rightarrow \operatorname{TS} 5(121.9 \mathrm{~kJ} / \mathrm{mol})$. Therefore, we can conclude that of the three paths, the $\mathrm{C}=\mathrm{S}$ path is better.

To future explore the first step reaction of $\mathrm{CS}_{2}$ hydrolysis, NBO analysis was performed for the transition states TS4, TS4', TS5, and TS5". Fig. 6 shows the NBO overlap between 04 lone pair electrons in TS4 and $\sigma^{\star}$ (S2-H5) antibonding receptors, and between 04 lone pair electrons in TS4 'and $\sigma^{\star}(03-\mathrm{H} 6)$ antibonding receptors. $\mathrm{LP}(\mathrm{O} 4) \rightarrow \sigma^{*}(\mathrm{~S} 2-\mathrm{H} 5)$ in TS4 $(527.2 \mathrm{~kJ} / \mathrm{mol})$ is greater than $\mathrm{LP}(04) \rightarrow \sigma^{\star}(03-\mathrm{H} 6)$ in TS2 '(500.7 $\mathrm{kJ} / \mathrm{mol}$ ). This shows that TS4 is easier to form than TS4', that is, the $\mathrm{C}=\mathrm{S}$ path and the $\mathrm{C}=\mathrm{S}, \mathrm{O}=\mathrm{C}$ path are more favorable than the $\mathrm{C}=0$ path. Similarly, the lone pair $\mathrm{O} 4$ donates electrons to the $\sigma^{*}(\mathrm{~S} 2-\mathrm{H} 6)$ antibonding receptor in TS5 and the lone pair 03 donates electrons to the $\sigma^{*}(04-\mathrm{H} 6)$ antibonding receptor in TS5. TS5 (594.6 kJ/mo) in LP (m1) and sigma * (S2 - H6) is greater than the TS2' (457.5 $\mathrm{kJ} / \mathrm{mol})$ in the LP (03) and sigma * $(\mathrm{m} 1-\mathrm{H} 6)$. It indicates that TS5 is easier to form than TS5 ", that is, the $\mathrm{C}=\mathrm{S}$ path is superior to the other two paths.

\subsection{Kinetic analysis of $\mathrm{CS}_{2}$ hydrolysis}

The above researchers have conducted many studies on the kinetics of hydrolysis reaction of $\mathrm{CS}_{2}$ through experiments. The experimental results show that the intermediate product of $\mathrm{CS}_{2}$ hydrolysis is COS. Meanwhile, the rate of $\mathrm{H}_{2} \mathrm{~S}$ produced by COS hydrolysis is much higher than that of COS produced by CS2 hydrolysis, which indicates that COS generated by $\mathrm{CS}_{2}$ hydrolysis is the rate-controlling step of the whole series hydrolysis reaction. In addition, the results of Huisman et al [49] show that the order of hydrolysis reaction of $\mathrm{CS}_{2}$ is closely related to the reaction temperature. When the hydrolysis temperature is lower than $252^{\circ} \mathrm{C}$, the hydrolysis reaction of $\mathrm{CS}_{2}$ is in the negative order for water; when the hydrolysis temperature is between $252-327^{\circ} \mathrm{C}$, the hydrolysis reaction of $\mathrm{CS}_{2}$ is in the positive order for water; when the hydrolysis temperature is higher than $327^{\circ} \mathrm{C}$, the hydrolysis reaction of $\mathrm{CS}_{2}$ is in the zero-order for water, and $\mathrm{CS}_{2}$ is not affected by temperature. The reaction rate equation at the temperature of $127 \mathrm{C} \sim 327^{\circ} \mathrm{C}$ was obtained. In addition, experimental studies [19] have shown that $\mathrm{CS}_{2}$ can also be hydrolyzed at room temperature, with good thermodynamic feasibility, but the conversion rate of $\mathrm{CS}_{2}$ is relatively low. Therefore, the study on the kinetics of hydrolysis reaction of $\mathrm{CS}_{2}$ to explore the reasons is conducive to further understanding the nature of hydrolysis reaction of $\mathrm{CS}_{2}$.

In this section, two reaction paths in the first step and three reaction paths in the second step of $\mathrm{CS}_{2}$ hydrolysis reaction mechanism are discussed in detail by using the kinetic knowledge, so as to further illustrate which reaction path is additionally favorable. The program uses the Shermo program [50] developed by Lutian. According to transition state theory [51-53], the activation enthalpy $\left(\Delta_{r} H_{m}\right)$, activation entropy $\left(\Delta_{r} S_{m}\right)$, and activation energy $\left(E_{a}\right)$ can be obtained from Eqs. 1-3 [50], respectively, while the rate constant $(k)$ can be expressed as in Eq. 4 [54-56]. 


$$
\Delta_{r} H_{m}=H(T S)-H(R)
$$

$$
\Delta_{r} S_{m}=S(T S)-S(R)
$$

$$
E_{a}=\Delta_{r} H_{m}+n R T
$$

$$
k=\frac{k_{b} T}{h}\left(\frac{p^{0}}{R T}\right)^{1-n} \exp \left(\frac{-\Delta_{r} H_{m}}{R T}\right) \exp \left(\frac{\Delta_{r} S_{m}}{R}\right)
$$

4

In the above formula, $T$ is the reaction temperature $(K), k$ is the rate constant, $p^{0}$ is standard atmospheric pressure, $R$ is the fundamental gas constant, $k_{b}$ is Boltzmann's constant, $h$ is Planck's constant, and $n$ is the number of reactants. $\Delta_{r} H_{m}, \Delta_{r} S_{m}, E_{a}, k$ of every elementary reaction at temperatures $298.15 \sim 1000 \mathrm{~K}$ (1 atm) were shown in Fig. 7.

As can be seen from Fig. 7, the reaction rates of all elementary reactions do not increase with the increase of temperature (298.15K 1000K). At the same time, for the first step of $\mathrm{CS}_{2}$ hydrolysis reaction, the reaction rates of both channel $A$ and channel $B$ are accelerated with the increase of temperature in the process of generating intermediates. However, in the process of forming the transition state, the reaction rate basically decreases as the temperature increases. It can be seen that the increase of reaction temperature does not increase the reaction rate of each elementary reaction. Besides, under the condition of the same reaction temperature, the reaction rate of each elementary reaction in channel $B$ must be equal to or greater than that of each elementary reaction in channel $A$, which indicates that channel $B$ is more likely to occur than channel $A$, which is consistent with the previous conclusion. In addition, as can be seen from Fig. 7, among channels A and B, TS1 has the highest activation energy, but its reaction rate Ink is the smallest, indicating that the step from IM1 to IM2-1 is the control step of the two reaction channels. At the same time, the activation energies of the two channels (as shown in Fig. 7) are relatively close, indicating that the two channels exist simultaneously and are in a competitive relationship with each other. By comparing the reaction rates at different temperatures, it is found that, in general, increasing the reaction temperature can increase the reaction rates of channel $A$ and channel $B$.

For the second step of $\mathrm{CS}_{2}$ hydrolysis reaction, it can also be found that the reaction rates of the three channels in the process of generating intermediates basically accelerate with the increase of temperature. In the process of forming the transition state, the reaction rate basically decreases as the temperature increases. At the same time, at the same reaction temperature, the reaction rate of each elementary reaction in channel $\mathrm{C}$ must be equal to or greater than that of each elementary reaction in channel $\mathrm{D}$ and 
channel $\mathrm{E}$, which indicates that channel $\mathrm{C}$ is more likely to occur than channel $\mathrm{D}$ and channel $\mathrm{E}$, which is also consistent with the previous conclusion. In addition, the activation energies of the three channels (as can be seen from Fig. 7) are relatively close, which indicates that the two channels exist simultaneously and are in a competitive relationship with each other. In addition, it can also be found from Fig. 7 that the total enthalpy change of each reaction channel is negative, indicating that $\mathrm{CS}_{2}$ is an exothermic reaction in the hydrolysis process. Therefore, increasing the reaction temperature is not conducive to its hydrolysis, which is consistent with the experimental results of the previous process condition (reaction temperature). Lixia Ling et al. ${ }^{19}$ obtained through a theoretical calculation that the optimal hydrolysis temperature of $\mathrm{CS}_{2}$ without catalyst was $252^{\circ} \mathrm{C}$.

\section{Conclusions}

In the present work, based on the B3LYP-D3(BJ)/6-311+G* theory, the hydrolysis mechanism of $\mathrm{CS}_{2}$ has been studied by DFT. Five detailed reaction mechanisms of $\mathrm{CS}_{2}$ hydrolysis have been proposed. And nine intermediates and nine transitions are stated to occur along the reaction pathways. The results show that the hydrolysis of $\mathrm{CS}_{2}$ will produce an intermediate (COS), and there are two steps. including the first step and the second step. The rate-determining step in the first step is the first elementary reaction, where $\mathrm{OH}$ and $\mathrm{H}$ in $\mathrm{H}_{2} \mathrm{O}$ attack $\mathrm{S}=\mathrm{C}$ in $\mathrm{CS}_{2}$, making the $\mathrm{C}=\mathrm{S}$ double bond a single bond. Similarly, the $\mathrm{OH}$ and $\mathrm{H}$ in the second step $\mathrm{H}_{2} \mathrm{O}$ attack the $\mathrm{C}=\mathrm{O}$ and $\mathrm{C}=\mathrm{S}$ in cosine, respectively. Through calculation, the ratedetermining steps of path 1 and path 2 have a higher barrier of $199.9 \mathrm{~kJ} / \mathrm{mol}$. However, the energy barrier of the step (IM2-1 $\rightarrow$ TS2) $(142.8 \mathrm{~kJ} / \mathrm{mol})$ in path 1 is higher than those for the step (IM2-1 $\rightarrow$ TS2') $(107.4$ $\mathrm{kJ} / \mathrm{mol})$ and the step (IM3'-1 $\rightarrow$ TS3') $(127.9 \mathrm{~kJ} / \mathrm{mol})$ in path 2 . So, path 2 is more favorable than path 1. Similarly, for the second step reaction of $\mathrm{CS}_{2}$ hydrolyses, the three paths are parallel and competitive. And the $\mathrm{C}=\mathrm{S}$ path is more favorable than the $\mathrm{C}=\mathrm{O}$ path and the $\mathrm{C}=\mathrm{S}$ and $\mathrm{O}=\mathrm{C}$ path. What's more, the reaction kinetics of hydrolysis of $\mathrm{CS}_{2}$ was studied, and it can be found that the hydrolysis of $\mathrm{CS}_{2}$ is an exothermic reaction, in other words, raising the temperature is not conducive to the reaction; it also can be found that the six reaction paths are parallel and competitive in the process of $\mathrm{CS}_{2}$ hydrolysis. This study is expected to provide a reference value for relevant researchers in this field and provide a new reference for studying the catalytic hydrolysis of $\mathrm{CS}_{2}$.

\section{Declarations}

\section{Funding}

This work was supported by the National Natural Science Foundation (Project No. 21966032), Yunnan University introduced talents for scientific research projects (Project No. C176220100034), Foundation of Educational Commission of Yunnan Province of China (Project No. 2021Y030), Graduate Research Innovation Project of School of Chemical Science and Engineering, Yunnan University and the Advanced analysis measurement center of Yunnan University. 


\section{Author contribution}

Lihong Tang: Conceptualization, Methodology, Formal analysis, Writing-Original draft preparation. Yue Wang, Guijian Zhang, Xin Shi, Ming Deng: Formal analysis, Visualization, Investigation. Zhiyuan Ning: Supervision, Validation, Writing- Reviewing and Editing.

\section{Availability of data and material}

All data generated or analyzed during this study are included in this article/supplementary materials.

\section{Code availability}

Not applicable.

Ethics approval Not applicable.

Consent to participate Not applicable.

Consent for publication Not applicable.

Conflict of interest The authors declare no competing interests.

\section{References}

1. Wang W, Fan L, Wang G (2017) Carbon disulfide $\left(\mathrm{CS}_{2}\right)$ adsorption and dissociation on the $\mathrm{Cu}(100)$ surface: A quantum chemical study. Applied Surface Science 414:92-100. https://doi.org/10.1016/j.apsusc.2017.04.082

2. Zeng Z, Dlugogorski B Z, Oluwoye I, Altarawneh M (2019) Combustion chemistry of carbon disulphide $\left(\mathrm{CS}_{2}\right)$. Combustion and Flame 210:413-425. https://doi.org/10.1016/j.combustflame.2019.09.005

3. Liu N, Song X, Wang C, Li K, Ning P, Sun X, Wang F, Ma Y (2020) Surface characterization study of corn-straw biochar catalysts for the simultaneous removal of $\mathrm{HCN}, \mathrm{COS}$, and $\mathrm{CS}_{2}$. New Journal of Chemistry 44:13565-13575. https://doi.org/10.1039/D0NJ01648A

4. Yue X, Wang H, Kong J, Li B, Yang J, Li Q, Zhang J (2020) A novel and green sulfur fertilizer from $\mathrm{CS}_{2}$ to promote reproductive growth of plants. Environmental Pollution 263:114448. https://doi.org/10.1016/j.envpol.2020.114448

5. Zhang X, Ponce V, Galvez-Aranda D E, Zhou G, Zhou H, Seminario J M (2021) CS $_{2}$ Removal from $C_{5}$ Distillates by Reactive Molecular Dynamics Simulations. Industrial \& Engineering Chemistry Research 60:5816-5825. https://doi.org/10.1021/acs.iecr.1c00530

6. DeMartino A W, Zigler D F, Fukuto J M, Ford P C (2017) Carbon disulfide. Just toxic or also bioregulatory and/or therapeutic?. Chemical Society Reviews 46:21-39. https://doi.org/10.1039/C6CS00585C 
7. Chen X, Li J, Jia C (2019) Thermodynamic Properties of Gaseous Carbon Disulfide. ACS Omega 4: 16121-16124. https://doi.org/10.1021/acsomega.9b02303

8. Chalansonnet M, Carreres-Pons M, Venet T, Thomas A, Merlen L, Boucard S, Pouyatos B (2020) Effects of co-exposure to $\mathrm{CS}_{2}$ and noise on hearing and balance in rats: continuous versus intermittent $\mathrm{CS}_{2}$ exposures. Journal of Occupational Medicine and Toxicology 15:1-11. https://doi.org/10.1186/s12995-020-00260-5

9. Zhang Y, Wang Y, Liu Y, Ai X, Zhang Z, Li J (2020) Measurement of the absorption cross sections of unstable CS based on the dynamic equilibrium of $\mathrm{CS}_{2}$ and $\mathrm{CS}$ in the photolysis of $\mathrm{CS}_{2}$. Journal of Quantitative Spectroscopy and Radiative Transfer 243:106836. https://doi.org/10.1016/j.jqsit.2020.106836

10. Wang F, Chen H, Sun X, Wang C, Ma Y, Song X, Li K,Ning P, He H (2021) Single atom Fe in favor of carbon disulfide $\left(\mathrm{CS}_{2}\right)$ adsorption and thus the removal efficiency. Separation and Purification Technology 258:118086. https://doi.org/10.1016/j.seppur.2020.118086

11. Iglesias-Sigüenza F J. (2008) Carbon disulfide $\left(\mathrm{CS}_{2}\right)$. Synlett 2009:157-158. https://doi.org/10.1055/s-2008-1067278

12. Song X, Ning P, Wang C, Li, K, Tang L, Sun X, Ruan H (2017) Research on the low temperature catalytic hydrolysis of $\mathrm{COS}$ and $\mathrm{CS}_{2}$ over walnut shell biochar modified by $\mathrm{Fe}-\mathrm{Cu}$ mixed metal oxides and basic functional groups. Chemical Engineering Journal 314:418-433. https://doi.org/10.1016/j.cej.2016.11.162

13. Zeng Z, Dlugogorski B Z, Oluwoye I, Altarawneh M (2019) Co-oxidation of methane $\left(\mathrm{CH}_{4}\right)$ and carbon disulfide $\left(\mathrm{CS}_{2}\right)$. Proceedings of the Combustion Institute 37:677-685. https://doi.org/10.1016/j.proci.2018.08.011

14. Danten Y, Cabaço M I, Coutinho J A P, Pinaud N, Besnard M (2016) DFT Study of the Reaction Mechanisms of Carbon Dioxide and its Isoelectronic Molecules $\mathrm{CS}_{2}$ and OCS Dissolved in Pyrrolidinium and Imidazolium Acetate Ionic Liquids. The Journal of Physical Chemistry B 120:524354. https://doi.org/10.1021/acs.jpcb.6b03229

15. Song X, Chen X, Sun L, Li K, Sun X, Wang C, Ning P (2020) Synergistic effect of $\mathrm{Fe}_{2} \mathrm{O}_{3}$ and CuO on simultaneous catalytic hydrolysis of $\mathrm{COS}$ and $\mathrm{CS}_{2}$ : Experimental and theoretical studies. Chemical Engineering Journal 399:125764. https://doi.org/10.1016/j.cej.2020.125764

16. Li K, Liu G, Gao T, Lu F, Tang L, Liu S, Ning P (2016) Surface modification of Fe/MCSAC catalysts with coaxial cylinder dielectric barrier discharge plasma for low-temperature catalytic hydrolysis of $\mathrm{CS}_{2}$. Applied Catalysis A: General 527:171-181. https://doi.org/10.1016/j.apcata.2016.09.007

17. Liu N, Ning P, Sun X, Wang C, Song X, Wang F, Li K (2021) Simultaneous catalytic hydrolysis of HCN, $\mathrm{COS}$ and $\mathrm{CS}_{2}$ over metal-modified microwave coal-based activated carbon. Separation and Purification Technology 259:11820. https://doi.org/10.1016/j.seppur.2020.118205

18. Saju A, Mondal A, Chattopadhyay T, Kolliyedath G, Kundu S (2020) $\mathrm{H}_{2} \mathrm{~S}$ Generation from $\mathrm{CS}_{2}$ Hydrolysis at a Dinuclear Zinc (II) Site. Inorganic Chemistry 59:16154-16159. 
https://doi.org/10.1021/acs.inorgchem.0c01194

19. Ling L, Zhang R, Han P, Wang B (2012) A theoretical study on the hydrolysis mechanism of carbon disulfide. Journal of molecular modeling 18:1625-1632. https://doi.org/10.1007/s00894-011-1183-4

20. Li K, Tang X, Yi H, Ning P, Kang D, Wang C (2012) Low-temperature catalytic oxidation of NO over $\mathrm{Mn}-\mathrm{Co}-\mathrm{Ce}-\mathrm{Ox}$ catalyst. Chemical engineering journal 192: 99-104.

https://doi.org/10.1016/j.cej.2012.03.087

21. Ning P, Li K, Yi H, Tang X, Peng J, He D, Zhao S (2012) Simultaneous catalytic hydrolysis of carbonyl sulfide and carbon disulfide over modified microwave coal-based active carbon catalysts at low temperature. The Journal of Physical Chemistry C 116:17055-17062.

https://doi.org/10.1021/jp304540y

22. Li K, Song X, Ning P, Yi H, Tang X, Wang C (2015) Energy utilization of yellow phosphorus tail gas: simultaneous catalytic hydrolysis of carbonyl sulfide and carbon disulfide at low temperature. Energy Technology 3:136-144. https://doi.org/10.1002/ente.201402122

23. Li Q, Yi H, Tang X, Zhao S, Zhao B, Liu D, Gao F (2016) Preparation and characterization of Cu/Ni/Fe hydrotalcite-derived compounds as catalysts for the hydrolysis of carbon disulfide. Chemical Engineering Journal 284:103-111. https://doi.org/10.1016/j.cej.2015.08.117

24. Song X, Wang C, Gasem K A M, Li K, Sun X, Ning P, Sun L (2019) New insight into the reaction mechanism of carbon disulfide hydrolysis and the impact of $\mathrm{H}_{2} \mathrm{~S}$ with density functional modeling. New Journal of Chemistry 43:2347-2352. https://doi.org/10.1039/C8NJ06078A

25. Fan Y, Zhuo Y, Zhu Z, Li L, Chen Q, Lou Y (2016) Density functional theory study on Hg removal mechanisms of Cu-impregnated activated carbon prepared by simplified method. Korean Journal of Chemical Engineering 33:2869-2877. https://doi.org/10.1007/s11814-016-0153-z

26. Wang J, Yang M, Deng D, Qiu S (2017) The adsorption of $\mathrm{NO}, \mathrm{NH}_{3}, \mathrm{~N}_{2}$ on carbon surface: a density functional theory study. Journal of molecular modeling 23:1-10. https://doi.org/10.1007/s00894017-3429-2

27. Trushin E, Thierbach A, Görling A (2021) Toward chemical accuracy at low computational cost: Density-functional theory with $\sigma$-functionals for the correlation energy. The Journal of Chemical Physics, 154:014104. https://doi.org/10.1063/5.0026849

28. Hai P, Wu C (2021) A comparative DFT study of the oxidation of Al crystals and nanoparticles. Physical Chemistry Chemical Physics, 23:24004-24015. https://doi.org/10.1039/D1CP03241K

29. Neela Y I, Guruprasad L (2021) Structures and energetics of darunavir and active site amino acids of native and mutant HIV-1 protease: a computational study. Structural Chemistry 1-13. https://doi.org/10.1007/s11224-021-01852-5

30. McKee M L (1993) Computational study of the addition of $\mathrm{OH}$ radical to $\mathrm{S}=\mathrm{C}=\mathrm{S}$. Chemical Physics Letters 201:41-46. https://doi.org/10.1016/0009-2614(93)85031-I

31. Rhodes C, Riddel S A, West J, Williams B P, Hutchings G J (2000) The low-temperature hydrolysis of carbonyl sulfide and carbon disulfide: a review. Catalysis today 59:443-464.

https://doi.org/10.1016/S0920-5861(00)00309-6 
32. Saheb V (2011) Quantum chemical and theoretical kinetics study of the $O\left({ }^{3} P\right)+\mathrm{CS}_{2}$ reaction. The Journal of Physical Chemistry A 115:4263-4269. https://doi.org/10.1021/jp200216b

33. Zhao J, Zhang Y, Gan L, Wang G (2021) Experimental and DFT study of UV-vis absorption spectra of azobenzene containing ester groups. Computational and Theoretical Chemistry 1200:113244. https://doi.org/10.1016/j.comptc.2021.113244

34. Tian H, He Z, Wang J, Jiao H, Hu Z, Yang Y (2020) Density Functional Theory Study on the Mechanism of Biochar Gasification in $\mathrm{CO}_{2}$ Environment. Industrial \& Engineering Chemistry Research 59:19972-19981. https://doi.org/10.1021/acs.iecr.0c04105

35. Lee C, Yang W, Parr R G (1988) Development of the Colle-Salvetti correlation-energy formula into a functional of the electron density. Physical review B 37:785-789. https://doi.org/10.1103/PhysRevB.37.785

36. Grimme S, Antony J, Ehrlich S, Krieg H (2010) A consistent and accurate ab initio parametrization of density functional dispersion correction (DFT-D) for the 94 elements H-Pu. The Journal of chemical physics 132:154104. https://doi.org/10.1063/1.3382344

37. Grimme S, Ehrlich S, Goerigk L (2011) Effect of the damping function in dispersion corrected density functional theory. Journal of computational chemistry 32:1456-1465. https://doi.org/10.1002/jcc.21759

38. Lu T, Chen F. F (2013) Revealing the nature of intermolecular interaction and configurational preference of the nonpolar molecular dimers $\left(\mathrm{H}_{2}\right)_{2},\left(\mathrm{~N}_{2}\right)_{2}$, and $\left(\mathrm{H}_{2}\right)\left(\mathrm{N}_{2}\right)$. Journal of molecular modeling 19:5387-5395. https://doi.org/10.1007/s00894-013-2034-2

39. Frisch MJ, Trucks GW, Schlegel HB, Scuseria GE, Robb MA, Cheeseman JR, Scalmani G, Barone V, Mennucci B, Petersson GA, Nakatsuji H, Caricato M, Li X, Hratchian HP, Izmaylov AF, Bloino J, Zheng G, Sonnenberg JL, Hada M, Ehara M, Toyota K, Fukuda R, Hasegawa J, Ishida M, Nakajima T, Honda Y, Kitao O, Nakai H, Vreven T, Montgomery JA, Peralta JE, Ogliaro F, Bearpar kM, Heyd JJ, Brothers E, Kudin KN, Staroverov VN, Kobayashi R, Normand J, Raghavachari K, Rendell A, Burant JC, lyengar SS, Tomasi J, Cossi M, Rega N, Millam JM, Klene M, Knox JE, Cross JB, BakkenV, Adamo C, Jaramillo J, Gomperts R, Stratmann RE, Yazyev O, Austin AJ, Cammi R, Pomelli C, Ochterski JW, Martin RL, Morokuma K, Zakrzewski VG, Voth GA, Salvador P, Dannenberg JJ, Dapprich S, Daniels AD, Farkas Ö, Foresman JB, Ortiz JV, Cioslowski J, Fox DJ (2009) Gaussian 09, Revision E.01. Gaussian Inc., Wallingford, $C T$

40. Trushin E, Thierbach A, Görling A (2021) Toward chemical accuracy at low computational cost: Density-functional theory with $\sigma$-functionals for the correlation energy. The Journal of Chemical Physics, 154:014104. https://doi.org/10.1063/5.0026849

41. Tian L, Fen C (2012) Multiwfn: A multifunctional wavefunction analyzer. Journal of Computational Chemistry 33:580-592. https://doi.org/10.1002/jcc.22885

42. Humphrey W, Dalke A, Schulten K (1996) VMD: visual molecular dynamics. Journal of molecular graphics 14:33-38. https://doi.org/10.1016/0263-7855(96)00018-5

43. Lu T (2021) TSTcalculator, http://sobereva.com/310. Accessed 22 Nov 2021 
44. Arokiyanathan A L, Lakshmipathi S (2021) Theoretical perspective on the interaction of $\mathrm{CO}_{2}$ and $\mathrm{H}_{2} \mathrm{O}$ molecules with functionalized magnesium and scandium phthalocyanines. Theoretical Chemistry Accounts 140:1-13. https://doi.org/10.1007/s00214-021-02732-1

45. Carpenter J E, Weinhold F (1988) Analysis of the geometry of the hydroxymethyl radical by the "different hybrids for different spins" natural bond orbital procedure. Journal of Molecular Structure: Theochem 169:41-62. https://doi.org/10.1016/0166-1280(88)80248-3

46. Liu J, Fang S, Wang Z, Yi W, Tao F M., Liu J. Y (2015) Hydrolysis of sulfur dioxide in small clusters of sulfuric acid: Mechanistic and kinetic study. Environmental science \& technology 49:13112-13120. https://doi.org/10.1021/acs.est.5b02977

47. Li K, Song X, Zhu T, Wang C, Sun X, Ning P, Tang L (2018) Mechanistic and kinetic study on the catalytic hydrolysis of COS in small clusters of sulfuric acid. Environmental Pollution 232:615-623. https://doi.org/10.1016/j.envpol.2017.10.004

48. Zierkiewicz W, Michalczyk M, Bieńko D, Michalska D, Zeegers-Huyskens T (2017) Nature of the interaction between ammonia derivatives and carbon disulfide. A theoretical investigation. International Journal of Quantum Chemistry, 117:e25369. https://doi.org/10.1002/qua.25369

49. Huisman H M, Van der Berg P, Mos R, Van Dillen A J, Geus J W. (1994) Hydrolysis of carbon sulfides on titania and alumina catalysts; the influence of water. Applied Catalysis A: General 115:157-171. https://doi.org/10.1016/0926-860X(94)80385-4

50. Lu T, Chen Q (2021) Shermo: A general code for calculating molecular thermochemistry properties. Computational and Theoretical Chemistry 1200:113249 DOI: 10.1016/j.comptc.2021.113249. https://doi.org/10.1016/j.comptc.2021.113249

51. Rietze C, Titov E, Lindner S, Saalfrank P (2017) Thermal isomerization of azobenzenes: on the performance of Eyring transition state theory. Journal of Physics: Condensed Matter 29:314002. https://doi.org/10.1088/1361-648X/aa75bd

52. Abdulsattar M A, Almaroof H M, Almaroof N M (2020) Transition state theory application to ZnO nanocluster sensitivity to $\mathrm{H}_{2}$ gas. Optik 219:165278. https://doi.org/10.1016/j.jleo.2020.165278

53. Hyre D E, Trong I L, Freitag S, Stenkamp R E, Stayton P S (2000) Ser45 plays an important role in managing both the equilibrium and transition state energetics of the streptavidin-biotin system. Protein Science 9:878-885. https://doi.org/10.1110/ps.9.5.878

54. Frisch C, Fersht A R, Schreiber G (2001) Experimental assignment of the structure of the transition state for the association of barnase and barstar. Journal of molecular biology 308:69-77. https://doi.org/10.1006/jmbi.2001.4577

55. Viegas L P (2018) Exploring the reactivity of hydrofluoropolyethers toward OH through a costeffective protocol for calculating multiconformer transition state theory rate constants. The Journal of Physical Chemistry A 122:9721-9732. https://doi.org/10.1021/acs.jpca.8b08970

56. de Carvalho E F V, Vicentini G D, Alves T V, Roberto-Neto O (2020) Variational transition state theory rate constants and $\mathrm{H} / \mathrm{D}$ kinetic isotope effects for $\mathrm{CH}_{3}+\mathrm{CH}_{3} \mathrm{OCOH}$ reactions. Journal of computational chemistry 41:231-239. https://doi.org/10.1002/jcc.26092 


\section{Figures}

\section{Figure 1}

Optimized geometries (of IM and TS) for the first step reaction mechanism of $\mathrm{CS}_{2}$ hydrolysis (bond distances in $\AA$ ).

\section{Figure 2}

The summary of the potential energy surface for the reaction $\mathrm{CS}_{2}$ hydrolysis was calculated at the B3LYP-D3/6-311+G* level.

\section{Figure 3}

NBO analysis of donor-acceptor interaction for TS2 and TS2' are from B3LYP-D3/6-311+G* calculations. Values are the second-order stabilization energies.

\section{Figure 4}

Optimized geometries (of IM and TS) for the second step reaction mechanism of $\mathrm{CS}_{2}$ hydrolysis (bond distances in $\AA$ ).

\section{Figure 5}

The summary of the potential energy surface for the reaction COS hydrolysis calculated at the B3LYPD3/6-311+G* level. 


\section{Figure 6}

NBO analysis of donor-acceptor interaction for the TS4, TS4', TS5 and TS5" are from B3LYP-D3/6$311+G^{*}$ calculations. Values are the second-order stabilization energies.

\section{Figure 7}

the activation enthalpy, activation entropy, activation and the rate constant energy of each step of elementary reaction at $298.15 \sim 1000 \mathrm{~K}$

\section{Supplementary Files}

This is a list of supplementary files associated with this preprint. Click to download.

- Authorbiography.docx

- GraphicalAbstract.docx

- Supplementaryinformation.docx 